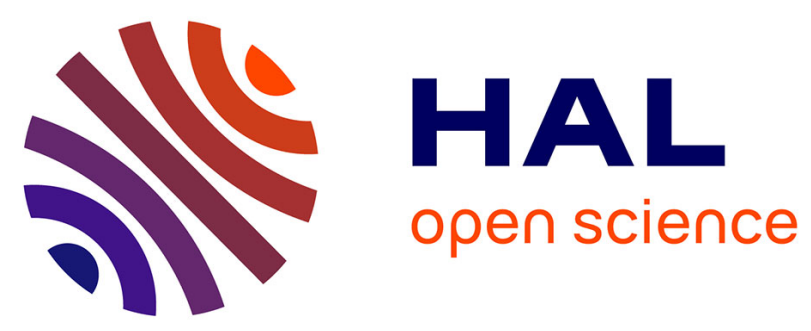

\title{
The Thermochemistry of Alkyne Insertion into a Palladacycle outlines the Solvation Conundrum in DFT
}

Milan R Milovanović, Mélanie Boucher, Yann Cornaton, Snežana D Zarić, Michel Pfeffer, Jean-Pierre Djukic

\section{To cite this version:}

Milan R Milovanović, Mélanie Boucher, Yann Cornaton, Snežana D Zarić, Michel Pfeffer, et al.. The Thermochemistry of Alkyne Insertion into a Palladacycle outlines the Solvation Conundrum in DFT. European Journal of Inorganic Chemistry, 2021, 2021 (45), pp.4690-4699. 10.1002/ejic.202100750 . hal-03413402

\section{HAL Id: hal-03413402 https://hal.science/hal-03413402}

Submitted on 3 Nov 2021

HAL is a multi-disciplinary open access archive for the deposit and dissemination of scientific research documents, whether they are published or not. The documents may come from teaching and research institutions in France or abroad, or from public or private research centers.
L'archive ouverte pluridisciplinaire HAL, est destinée au dépôt et à la diffusion de documents scientifiques de niveau recherche, publiés ou non, émanant des établissements d'enseignement et de recherche français ou étrangers, des laboratoires publics ou privés. 


\title{
The Thermochemistry of Alkyne Insertion into a Palladacycle outlines the Solvation Conundrum in DFT.
}

\author{
Milan R. Milovanović, ${ }^{[a],[b]}$ Mélanie Boucher, ${ }^{[a]}$ Yann Cornaton, ${ }^{[a]}$ Snežana D. Zarić, ${ }^{[c]}$ Michel Pfeffer ${ }^{[a]}$ \\ and Jean-Pierre Djukic ${ }^{[a],}$
}

[a] Dr M. R. Milovanović, M. Boucher, Dr Y. Cornaton, Dr M. Pfeffer, Dr J.P. Djukic

Laboratoire de Chimie et Systémique Organométalliques, UMR 7177 CNRS / University of Strasbourg

4 rue Blaise Pascal, F-67000 Strasbourg Cedex, France

E-mail: djukic@unistra.fr

World wide web: http://lcsom.u-strasbg.fr

[b] Dr M. R. Milovanović

Innovation center, Faculty of Chemistry, University of Belgrade

Studenski Trg 12-16, SRB-11000 Belgrade, Serbia

[c] Prof. Dr S. D. Zarić

Faculty of Chemistry, University of Belgrade

Studenski Trg 12-16, SRB-11000 Belgrade, Serbia

Supporting information for this article is given via a link at the end of the document

\begin{abstract}
In an effort to determine the thermochemistry of established organometallic transformation, the well documented reaction of alkynes with a palladacycle was investigated by isothermal titration calorimetry (ITC). Although the mechanism of the insertion of unsaturated substrates into the $\mathrm{Pd}-\mathrm{C}$ bond of cyclopalladated compounds is known, so far no information is known about their thermochemistry. The enthalpies of the reactions of $\mathrm{Ph}$ $\mathrm{C} \equiv \mathrm{C}-\mathrm{Ph}$ and $\mathrm{MeOC}(\mathrm{O})-\mathrm{C} \equiv \mathrm{C}(\mathrm{O}) \mathrm{COMe}$ with the bisacetonitrilo salt of the $\mathrm{N}, \mathrm{N}$-benzylamine palladacycle were determined by ITC in chlorobenzene after having optimized the conditions to ensure that only the double and a single insertion of alkynes were occurring respectively. The reaction energy profile established by DFT for the double insertion process involving $\mathrm{Ph}-\mathrm{C} \equiv \mathrm{C}$ - $\mathrm{Ph}$ confirmed earlier conclusions on the rate determining character of the first insertion. Further computations of reaction enthalpies reveal significant discrepancies between ITC and DFT-D/continuum solvation enthalpies, that are suspected to arise from an unexpected explicit noncovalent interaction of $\mathrm{PhCl}$ with the components of the reaction.
\end{abstract}

\section{Introduction}

The determination of thermochemical parameters of reactions $\left(\Delta H_{\mathrm{r}}, \Delta G_{\mathrm{r}}\right.$ and $\left.\Delta S_{\mathrm{r}}\right)$ in solution is particularly important to gauge the pertinence of using static DFT theoretical methods with solvation models to model "real-world" reactions. ${ }^{[1]}$ Indeed, if London dispersion was long ignored in DFT, its reinstatement in new DFT- $\mathrm{D}^{[2]}$ methods required probing the latter for improved performance in reproducing observables such as reaction enthalpies, which was done successfully in a few cases $^{[1 a]}$ using Isotherm Titration Calorimetry (ITC)..$^{[3]}$ An accurate determination of reaction enthalpies by ITC is achievable when the studied process is irreversible, has fast kinetics and is not contaminated by significant side reactions. ITC is particularly suitable for reactions in a homogenous phase and reliable as long as no gases or solids are released in the medium during titration. $^{[4]}$ ITC is a powerful tool to investigate pre-catalyst activation and probe mechanistic schemes by static DFT. ${ }^{[4 a]}$
Furthermore, ITC can be used to extract kinetic information ${ }^{[5]}$, which requires nonetheless to back all ITC experiments with reaction monitoring by other spectroscopic means.

Static DFT methods associated to a continuum solvation model remain to date one of the most time-effective expedient to draw energy profiles of reactions,${ }^{[6]}$ although most continuum (implicit) solvation models have crippling limitations. ${ }^{[7]}$ The nature of the reactants, their ionic or neutral status, their polarization and Lewis basic/acid character, and above all the structuration of the solvent in the reactant-solvent interaction may lead to large discrepancies between measured enthalpies and the ones computed by static DFT dubbed with continuum screening models of solvation. ${ }^{[8]}$ The first known reason for such discrepancies resides in explicit solvent interactions with reactants that are hardly predictable and even harder to include in DFT reaction modelling. The few solutions based on molecular dynamics that are emerging with the aim of minimizing user's bias in positioning explicit solvent molecules ${ }^{[9]}$ are still hardly transposable to full scale reaction energy profile search. ${ }^{[10]}$ Another reason for discrepancies, still not well recognized, is the dynamic nanostructuration of solvents into adaptive polar and apolar domains ${ }^{[11]}$ that conventional static DFT-continuum solvation cannot address readily.

However, we have already shown that in some cases static DFT-D (i.e dispersion corrected DFT) dubbed with a standard continuum screening solvation model (such as $\mathrm{PCM}^{[12]}$ or $\mathrm{COSMO}^{[13]}$ and COSMO-RS ${ }^{[14]}$ ) can reproduce with moderate discrepancies ${ }^{[1 a, 4 a, 8 b]}$ experimental enthalpies of reactions obtained by ITC. Such observations were made for reactions carried out in the moderately polar $\mathrm{PhCl}$. Other series of studies aiming at establishing the thermochemical parameters of various chemical processes spanning in complexity from the host-guest noncovalent reclusion ${ }^{[8 b, 8 c]}$ of organometallic species in water, the simple ligand exchange or slightly more complex but known transformations of organometallic complexes in $\mathrm{PhCl}^{[1 \mathrm{a}, 4 \mathrm{a}, 5,8]}$ In several instances though, discrepancies between experimentally and theoretically determined reaction $\Delta_{\mathrm{r}} \mathrm{H}$ in $\mathrm{PhCl}$ were often assigned to the yet elusive explicit solvation. ${ }^{[5]}$ In this study, we 
address another prototypical organometallic reaction, i.e. the well-known alkyne insertion into the $\mathrm{C}_{\mathrm{Ar}} \mathrm{Pd}$ bond of a cationic palladacycle.

Among many applications of cyclopalladated compounds that have been highlighted, ${ }^{[15]}$ the functionalization of the carbon atom directly linked to $\mathrm{Pd}$ has been investigated as early as in 1967. ${ }^{[16]}$ Indeed, Tsuji and Takahashi reported the insertion of $\mathrm{CO}$ into the Pd-C bond of cyclopalladated azobenzene that led to indazolone by virtue of a novel type of reductive elimination process. Insertion of alkynes into $\mathrm{Pd}-\mathrm{C}$ bonds of palladacycles is one of the representative reactions that make cyclopalladated compounds attractive starting materials for organic synthesis. ${ }^{[17]}$ Some of $\mathrm{us}^{[18]}$ and others ${ }^{[19]}$ have reported the insertion of various kinds of alkynes into the $\mathrm{Pd}-\mathrm{C}$ bond of these reactive organopalladium species. That finding has proven useful as a preparative method for a range of palladacycles containing various functionalities. The mechanism of the insertion of the alkynes into the $\mathrm{Pd}-\mathrm{C}$ bond of palladacycles has been reported. ${ }^{[20]}$ In general, this reaction proceeds via a step-wise process beginning with the coordination of the alkyne to the palladium and the subsequent migratory insertion of the alkyne into $\mathrm{Pd}-\mathrm{C}$ bond. Usually, the first insertion is the rate determining step within multiple insertions. It was found that electron deficient alkynes (for instance dimethyl acetylenedicarboxylate (DMAD, 2a, see Eqn 1) led to single insertion while the electron rich alkynes (for instance diphenylethyne, 2b, see Eqn 2) gave a double inserted reaction product. Whilst kinetics of the insertion reactions of the alkynes into the palladacycles have been described ${ }^{[20]}$ no information of their thermochemistry has been provided yet. We undertook a round of isothermal calorimetric measurements on various insertion reactions (Eqn 1 and 2), to (i) investigate accurately the thermochemistry of the single and double insertions of alkynes into the Pd-C bond of cyclopalladated derivatives and (ii) estimate the overall performance of ITC and DFT dubbed with standard corrections for solvation by continuum screening models.

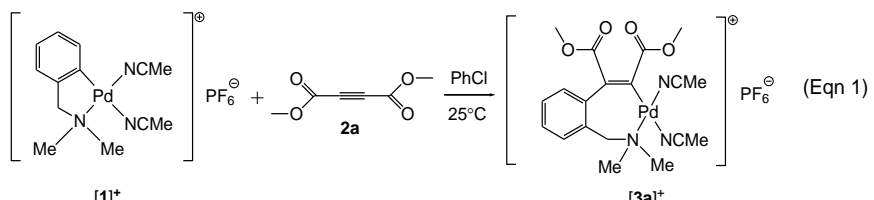
$[3 \mathrm{a}]^{+}$

$$
1+P h \underset{2 b}{=} P h \frac{\mathrm{PhCl}}{25^{\circ} \mathrm{C}}
$$$$
[3]^{+}
$$

\section{Results and Discussion}

Earlier studies on alkyne insertion reactions into the $\mathrm{Pd}-\mathrm{C}$ bond of cyclopalladated compounds formed with $\mathrm{N}, \mathrm{N}$ dimethylbenzylamine ligands were performed with chloride bridged cyclopalladated dimers. ${ }^{[20]}$ It was shown that alkynes bearing two electron-withdrawing groups (e.g. $\mathrm{CF}_{3}$ or $\mathrm{CO}_{2} \mathrm{Me}$ ) undergo the insertion of one alkyne only, whereas alkynes bearing electron-donating groups (e. g. $\mathrm{C}_{6} \mathrm{H}_{5}$, Me or Et) lead to the insertion of two alkynes into the $\mathrm{Pd}-\mathrm{C}$ bond, the second insertion being often qualified as very fast for electron-rich alkynes, the insertion of the first alkyne being rate-determining. With electron poor alkynes the insertion was often too slow to be properly studied. We have also previously studied the reactions, with the same reagents, of chloride-free cyclopalladated monomers in which the coordination of the cyclopalladated moiety was completed by two acetonitrile units. However, in these cases we did not perform the isolation of the organometallic intermediates as the reactions were done at higher temperatures (under reflux of chlorobenzene) that led directly to the organic molecules in which one or two alkyne reagents have reacted with the cyclopalladated unit.

In the present work, the insertion reactions of the alkynes 2a-b (Eqns 1-2) into cationic palladacycle $[1] \mathrm{PF}_{6}$ were studied experimentally by jointly carrying out verification of reaction's chemical neatness in the synthesis of the two alkyne insertion products [3a]PF 6 and [3b]PF 6 and ITC-based determination of thermochemical parameters. Theoretical computations of the thermochemistry were performed by static DFT-D ${ }^{[2 a, 2 c, 21]}$ calculations using $\mathrm{COSMO}^{[13]}$ and $\mathrm{PCM}^{[12]}$ solvation continuum models with the dispersion corrected PBE functional.

As ITC experiments are lengthy, care was lent to optimizing the conditions of thermograms acquisition and to verifying that no unwanted chemical process interferes with the main reaction. Indeed, it was shown with cyclopalladated derivatives that up to three alkynes can potentially insert into the $\mathrm{Pd}-\mathrm{C}$ bond even when deactivated alkynes bearing electron-attractive substituents are used. [22]

The previously proposed mechanism of the studied insertion reactions $^{[20,23]}$ implies the approach of the alkyne perpendicularly to the coordination square plane of the palladium followed by the $\pi$-coordination of the alkyne and the decoordination of an adjacent $\mathrm{MeCN}$ ligand. At that point occurs the migration of the chelate's carbanionic carbon on the alkyne's triple bonded carbon establishing a new carbon-carbon bond, whilst another triple bonded carbon may enter palladium's coordination sphere. If the alkyne is $\mathbf{2 a}$, the first insertion ends by the recoordination of the $\mathrm{MeCN}$ resulting in an isolable single inserted product [3a]PF 6 (Eqn 1). However, if the used alkyne is $\mathbf{2 b}$, the formed single inserted product rather reacts due to its extreme reactivity with another molecule of alkyne leading to [3b]PF 6 upon insertion of second alkyne into the palladacycle by releasing one of the coordinated $\mathrm{MeCN}$ molecules. According to the literature ${ }^{[20]}$ the insertion of $\mathbf{2 b}$ should lead exclusively to the double inserted product [3b]PF 6 (Eqn 2) notwithstanding the molar ratio of the reactants. In contrast, the insertion of $2 \mathrm{a}$ depends on the molar ratio and additional reactions such as ligand exchange and double or even triple insertion of the alkyne may occur (Cf SI, Scheme S1). The reaction energy profile of the double insertion reaction of $\mathbf{2} \mathbf{b}$ with [1] $\mathrm{PF}_{6}$, which happens to be more selective than the insertion reaction of $\mathbf{2} \mathbf{a}$, was therefore investigated first (vide infra) to uncover the possible origins of the difference of selectivity. 


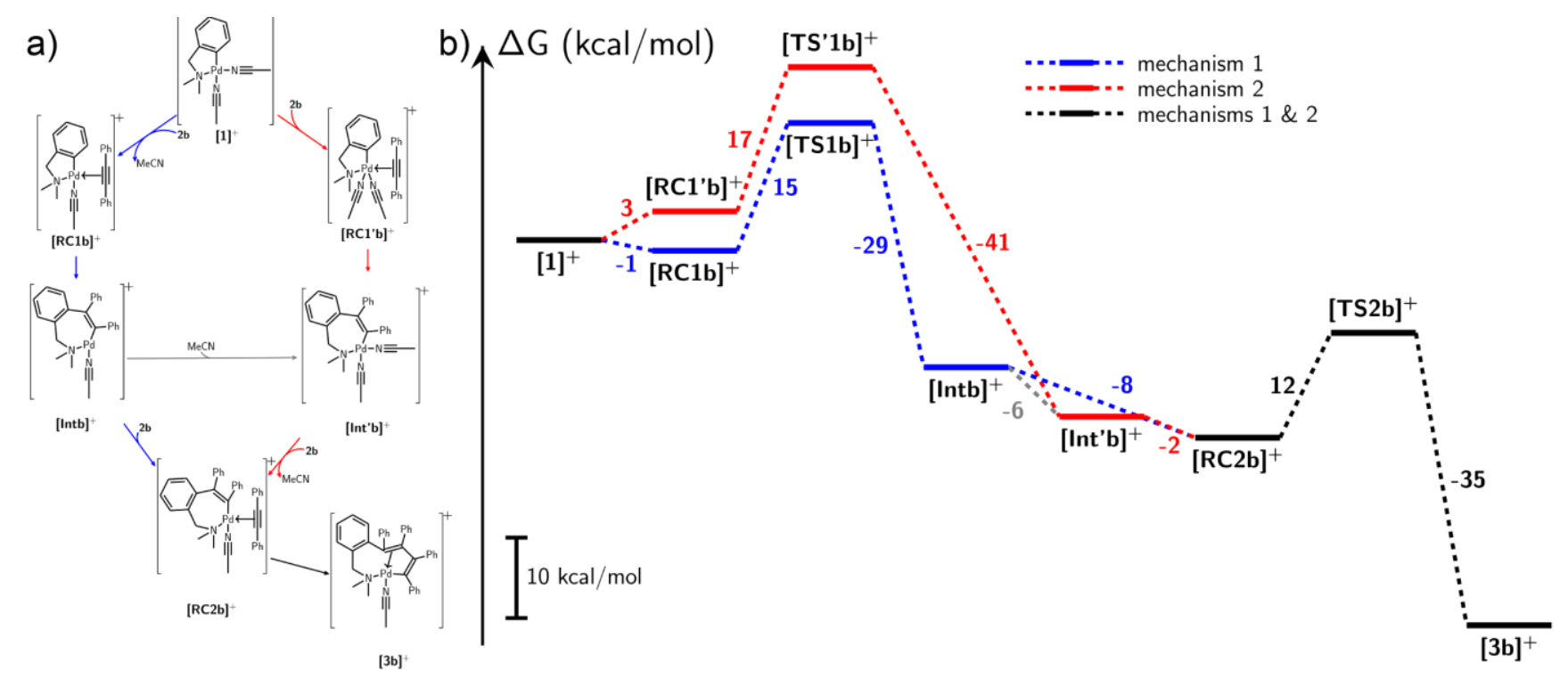

Figure 1. a) The mechanisms of insertion of alkyne $\mathbf{2 b}$ to compound [1] $]^{+}$implying two scenarios, namely the prior displacement of MeCN by the alkyne to give intermediate $[\mathbf{R C} \mathbf{C} \mathbf{b}]^{+}$or the formation of a $\pi$-reactant complex $\left[\mathbf{R C} \mathbf{C}{ }^{\prime} \mathbf{b}\right]^{+}$. b) Reaction energy profile for the reaction of $[\mathbf{1}]^{+}$with $\mathbf{2 b}$ in $\mathbf{C O S M O}(\mathrm{PhCl})$ without accounting for the $\mathrm{PF}_{6}$ counter-anion.

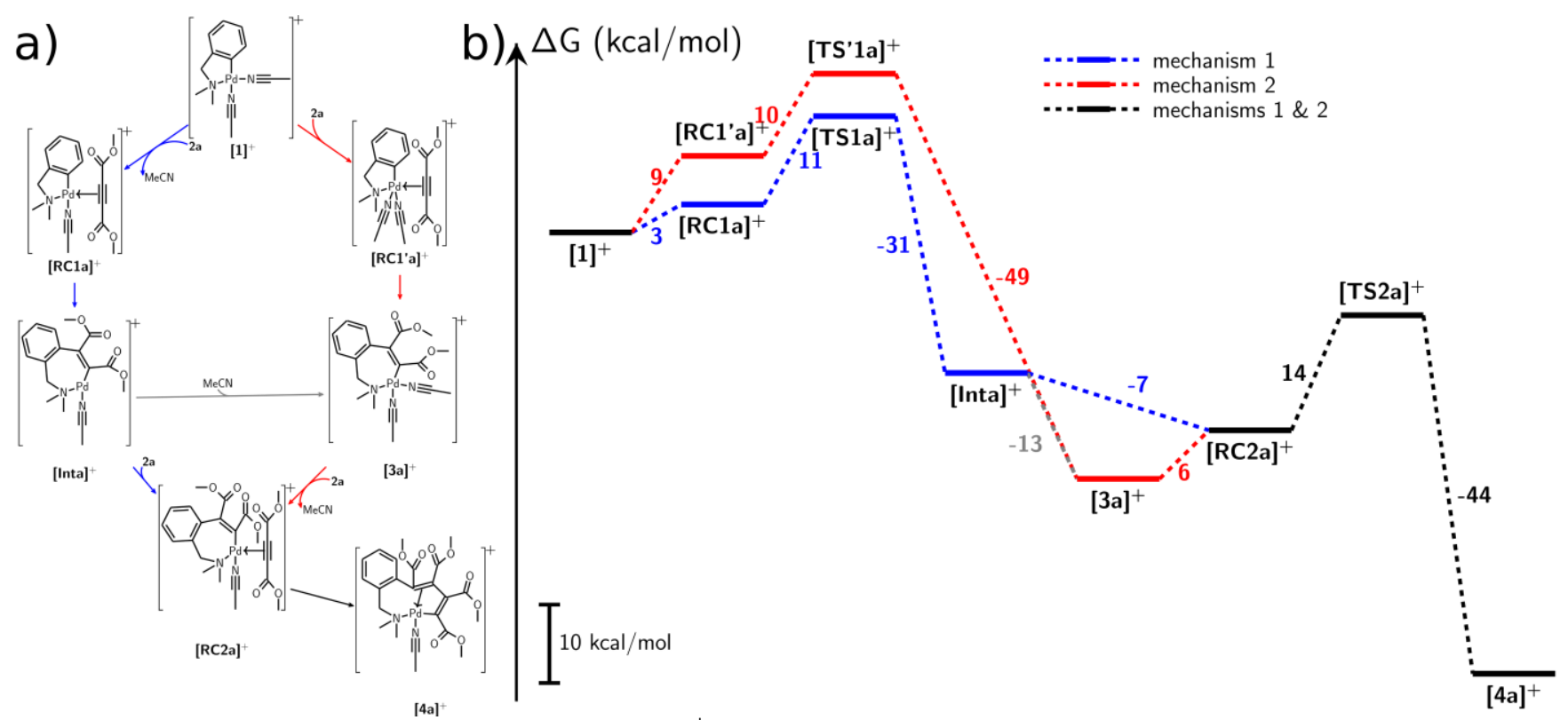

Figure 2. a) The mechanisms of insertion of alkyne $\mathbf{2 a}$ to compound [1] ${ }^{+}$implying two scenarios, namely the prior displacement of MeCN by the alkyne to give intermediate $[\mathbf{R C 1} \mathbf{a}]^{+}$or the formation of a $\pi$-reactant complex $[\mathbf{R C 1} \text { 'a }]^{+}$. b) Reaction energy profile for the reaction of $[\mathbf{1}]^{+}$with $\mathbf{2 a}$ in $\mathrm{COSMO}(\mathrm{PhCl})$ without accounting for the $\mathrm{PF}_{6}$ counter-anion.

DFT-D computation of the reaction profile of the double insertion reaction of $\mathbf{2 b}$ with $[1]^{+}$. To expedite the reaction energy profile, the counter anion was not included in the theoretical exploration of the reaction mechanism of formation of $[\mathbf{3 b}]^{+}$from [1] $]^{+}$and $\mathbf{2 b}$. Like shown farther, accounting for $\mathrm{PF}_{6}$ has an effect on the overall reaction energetics and the corresponding $\Delta_{\mathrm{r}} G$ and $\Delta_{\mathrm{r}} H$ values as continuum screening solvation model corrections such as the one used herein have a known flaw with charged systems. ${ }^{[2]}$ However, it is speculated that this flaw does not impact significantly the relative barriers of activation, which provide key information on the rate determining step of this double alkyne insertion reaction. When not accounting for the counter anion, $\Delta_{\mathrm{r}} G$ and $\Delta_{\mathrm{r}} H$ at $298.15 \mathrm{~K}$ amount -46 and $-67 \mathrm{kcal} / \mathrm{mol}$ respectively under standard COSMO solvation ${ }^{[13]}$, using scalar correction for relativistic effects (Zeroth Order Relativistic Approximation ${ }^{[25]}$ ) with the PBE-D4(EEQ) functional. The determined reaction energy profile indicates that three events are relevant in the mechanism of double insertion: the two successive insertions of $\mathbf{2 b}$ in a $\mathbf{P d}$ $\mathrm{C}$ bond, and the release of an acetonitrile ligand.

From there, two different mechanistic pathways have been considered:

a) $[1]^{+}$undergoes first a ligand exchange between acetonitrile and $\mathbf{2} \mathbf{b}$, the two insertions occur successively 
through a 3-coordinate intermediate complex Intb. (mechanism 1, blue pathway in Figure 1)

b) a first insertion of $\mathbf{2 b}$ into the Pd-C bond of $\mathbf{1}$ and the 5coordinate intermediate complex [Int'b] ${ }^{+}$undergoes a ligand exchange between acetonitrile and $\mathbf{2} \boldsymbol{b}$ before the second insertion (mechanism 2, red pathway in Figure 1).

Considering mechanism 1, the first step of ligand exchange is slightly exergonic $(\Delta G=-1 \mathrm{kcal} / \mathrm{mol})$. From there, the insertion of $\mathbf{2 b}$ is exergonic $(\Delta G=-14 \mathrm{kcal} / \mathrm{mol})$ through a $15 \mathrm{kcal} / \mathrm{mol}$ reaction barrier. At this point, the 3-coordinate intermediate [Intb] ${ }^{+}$could undergo the coordination of a second molecule of 2b $(\Delta G=-8 \mathrm{kcal} / \mathrm{mol})$ leading to the formation of the reactant complex $[\mathbf{R C 2} \mathbf{b}]^{+}$, or the recoordination of an acetonitrile molecule $(\Delta G=-6 \mathrm{kcal} / \mathrm{mol}$, gray pathway in Figure 1) leading to the formation of the monoinsertion complex [Int'b] $]^{+}$. The coordination of a second molecule of $\mathbf{2} \mathbf{b}$ being more stabilizing than the recoordination of an acetonitrile one, the monoinsertion product [Int'b] ${ }^{+}$is not likely to be observed and the system will spontaneously undergo a double insertion.

Considering mechanism 2 (Figure 1), the first step is the formation of the 5 -coordinate reactant complex [RC1'b] ${ }^{+}$by coordination of $\mathbf{a} \mathbf{2 b}$ on the $\mathrm{Pd}$ of $[1]^{+}(\Delta G=+3 \mathrm{kcal} / \mathrm{mol})$. Insertion of the alkyne in the $\mathrm{Pd}-\mathrm{C}$ bond is exergonic $(\Delta G=-41$ $\mathrm{kcal} / \mathrm{mol})$. [Int'b] ${ }^{+}$then undergoes an exergonic ligand exchange between acetonitrile and $\mathbf{2 b}(\Delta G=-2 \mathrm{kcal} / \mathrm{mol})$ to form the reactive complex $[\mathbf{R C 2} \mathbf{b}]^{+}$. From there, mechanisms 1 and 2 converge for the formation of $[\mathbf{3 b}]^{+}$by insertion of the alkyne in the $\mathrm{Pd}-\mathrm{C}$ bond of $[\mathbf{R C 2} \mathbf{b}]^{+}(\Delta G=-23 \mathrm{kcal} / \mathrm{mol})$ through a reaction barrier of $12 \mathrm{kcal} / \mathrm{mol}$. Even if mechanism 1 seems more likely than mechanism 2 (exergonic generation of the first reactive complex and lower reaction barrier), both mechanisms are energetically plausible and might take place in the reactive medium.

DFT-D computation of the reaction profile of the single- and double insertion reaction of $2 a$ with $[1]^{+}$. The theoretical exploration of the reaction mechanism of the single- and double insertion of $2 \mathrm{a}$ in the $\mathrm{Pd}-\mathrm{C}$ bond of $[1]^{+}$, leading respectively to $[3 a]^{+}$and $[4 \mathbf{a}]^{+}$(Figure 2), was carried out in the same manner as for the formation of $[\mathbf{3 b}]^{+}$from $\mathbf{2 b}$ and $[\mathbf{1}]^{+}$(Figure 1 ). The same mechanistic pathways as for the formation of $[\mathbf{3 b}]^{+}$were considered (Figure 2).

The same qualitative observations as for the insertions of $\mathbf{2 b}$ can mainly be drawn for the insertions of $\mathbf{2 a}$. Two differences can however be noticed between the insertions of $\mathbf{2 a}$ and $\mathbf{2} \mathbf{b}$ in the $\mathrm{Pd}-\mathrm{C}$ bond of $[1]^{+}$:

a) In the $2 \mathbf{a}$ insertion case, the first step of mechanism 1 , the ligand exchange, is endergonic $(\Delta G=3 \mathrm{kcal} / \mathrm{mol})$ while it was exergonic in the $\mathbf{2} \mathbf{b}$ insertion case.

b) From the 3-coordinate intermediate complex Inta, the recoordination of an acetonitrile molecule $(\Delta G=-13 \mathrm{kcal} / \mathrm{mol}$, gray pathway in Figure 2) is more exergonic than the coordination of a second $2 \mathrm{a}$ molecule $(\Delta G=-7 \mathrm{kcal} / \mathrm{mol})$.

The latter difference can be accounted for to explain that the mono-insertion product can be observed when $\mathbf{2 a}$ undergoes insertion, while it is not when $\mathbf{2} \mathbf{b}$ undergoes insertion. However, the coordination of a second $\mathbf{2 a}$ molecule on Inta requiring only $6 \mathrm{kcal} / \mathrm{mol}$ more than the recoordination of an acetonitrile molecule, the formation of the double insertion product $[4 \mathbf{a}]^{+}$is largely favourable as this step is exergonic $(\Delta G=-30 \mathrm{kcal} / \mathrm{mol})$.
Chemical neatness assessment and ITC experiment optimisation. ITC experiments carried out by sequential injection of a reagent into a cell containing its counterpart allow access to the so-called raw reaction enthalpy $\Delta H_{\mathrm{r}}$ with great accuracy if the reaction is irreversible, such as the alkyne insertion reactions treated herein. This is done by summing up heat flows over molar amounts of reagents up to the point of athermicity when no more heat is produced by additional injections of reagent.

In a typical sequential isothermal calorimetric titration the addition of portions of a solution of a reagent from a servocontrolled syringe into the measure cell containing the reagent's counterpart differs from a conventional reaction monitoring by spectroscopic means. As the injection of the reagent proceeds, a heat flow surge occurs that requires the system to compensate it to return to the reference baseline. The compensation current applied to the Peltier unit of the calorimeter gives access to the total heat flow produced by each injection of reagent. However the time required to return the cell to the reference initial heat flow baseline status is hardly predictable and requires adjustments so as to avoid cumulative overlaps of heat tails from previous injections with that of a new injection that could cause baseline drifts. Depending on the kinetics of the reaction, the optimization of this "relaxation" delay is crucial. Of equal importance is the neatness of the chemical process to be studied by ITC, that is the absence of interfering side reactions initiated by a large excess of one of the two reagents, which would introduce heat biases.

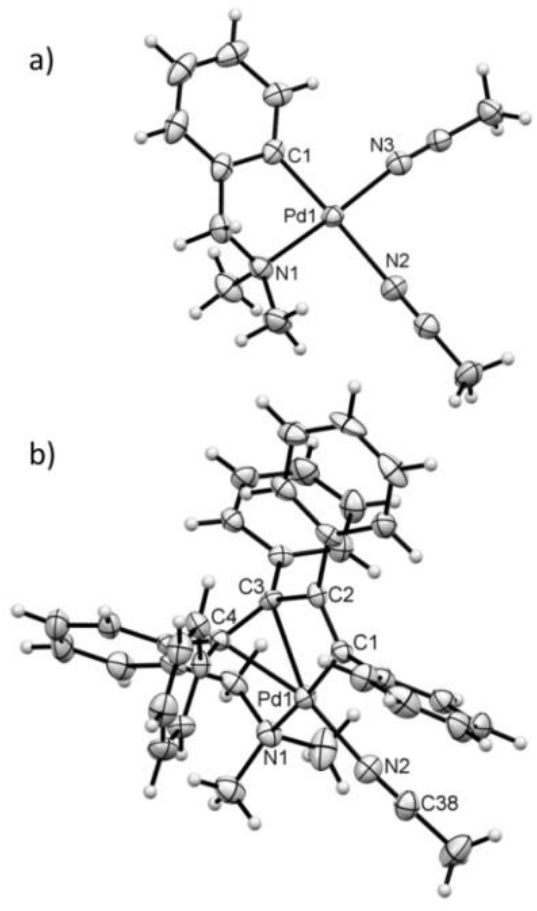

Figure 3. ORTEP drawings of the structures of (a) $[1]^{+}$and (a) $[3 \mathbf{b}]^{+}$with thermal ellipsoids at $50 \%$ probability. The $\mathrm{PF}_{6}{ }^{-}$anion and molecules of solvent have been omitted for clarity. Selected interatomic distances $(\AA)$ and angles $\left({ }^{\circ}\right)$ for 1: C1-Pd1 1.970(2), Pd1-N3 2.025(2), Pd1-N1 2.070(2), Pd1-N2 2.127(2), C1-Pd1-N1 82.45(9), N3-Pd1-N2 88.18(8). Selected interatomic distances $(\AA)$ and angles $\left({ }^{\circ}\right)$ for $[3 \mathrm{~b}]^{+}$: C1-C2 1.336(10), C2-C3 1.500(9), C3C4 1.399(9), C1-Pd1 2.000(7), C2-Pd1 2.588(7), C3-Pd1 2.215(7), C4-Pd1 2.236(7), N1-Pd1 2.215(6), N2-Pd1 2.043(6), C1-C2-C3 107.9(6), C4-C3-C2 118.1(6). 
Optimal conditions for the ITC measurements were therefore sought by complementary experiments:

a) reactions were monitored by ${ }^{1} \mathrm{H}$ NMR vs. time, monitored in NMR sample tubes using deuterated chloroform as solvent with different molar ratios of the palladacycle [1]PF 6 and the alkynes 2a-b,

b) reaction products, $[\mathbf{3} \mathbf{a}-\mathbf{b}] \mathrm{PF}_{6}$, were isolated for characterization.

It was found that mixing [1]PF 6 with $\mathbf{2 a}(1: 1)$ or $\mathbf{2} \mathbf{b}(1: 2)$ in chloroform- $d$ at room temperature resulted in good yields in both [3a]PF 6 and [3b]PF 6 after $1 \mathrm{~h}$ according to ${ }^{1} \mathrm{H}$ NMR spectra (Figure S1-2). Compounds [3a-b]PF 6 , were further isolated and characterized. Single crystals were isolated allowing to structurally characterize [3b]PF 6 by $\mathrm{X}$-ray diffraction analysis. Figure 3 displays the structures of [1] $\mathrm{PF}_{6}$ and $[3 \mathbf{b}] \mathrm{PF}_{6}$.

The solutions related to the reaction of [1]PF 6 and $\mathbf{2} \mathbf{a}-\mathbf{b}$ in $\mathrm{CDCl}_{3}$ were monitored with different molar ratios of alkyne and various reaction times to track any possible unwanted reaction that could occur with the excess of alkyne, given that the estimated duration of one ITC run could span 8.5 to $120 \mathrm{~h}$. ${ }^{1} \mathrm{H}$ NMR monitoring (cf SI, Figure S3-8) showed that the formation of products of double and triple insertion of alkyne 2a was significant after $15 \mathrm{~h}$ of reaction when a 1:2 ratio of [1]PF 6 and 2a was used. However, these two latter processes were estimated to be much slower than the first insertion reaction, already found to be rather slow. As a compromise it was decided to restrict the total duration of the ITC titration to that of the first insertion step by limiting the amount of available alkyne. To achieve this, the solution of palladacycle [1]PF 6 would be placed in the measure cell while the solution of $2 \mathbf{a}$ would be sequentially injected in small portions from the servo-controlled syringe. It was also found that long time delays (10000 s) between two subsequent injections were required to achieve full relaxation to baseline.

The double insertion reaction of $\mathbf{2} \mathbf{b}$ with [1] $\mathrm{PF}_{6}$ was monitored at various reaction times, i.e after $1.8 \mathrm{~h}, 3 \mathrm{~h}$ and $24 \mathrm{~h}$ as well as with $1: 1,1: 2$ and $1: 4$ molar ratios of the reactants $(\mathbf{1}: \mathbf{2 b})$. From the relevant ${ }^{1} \mathrm{H}$ NMR spectra (cf SI) solely the product of alkyne's double insertion was detected, no product of the single or multiple insertion reaction being observed though. As an ultimate verification, a large excess (10 equivalents) of $\mathbf{2} \mathbf{b}$ was used with reaction times with [1] $\mathrm{PF}_{6}$ spanning from $0.7 \mathrm{~h}$ to 20.5 $\mathrm{h}$ and evaluated by ${ }^{1} \mathrm{H}$ NMR spectroscopy (cf. SI). It was concluded that the reaction gives solely $[3 \mathbf{b}] \mathrm{PF}_{6}$ regardless of the reaction times and excess of alkyne. A time delay between two consecutive injections of $3000 \mathrm{~s}$ was found to be optimal to acquire an accurate ITC thermogram.

In conclusion, ITC experiments were set up in two different manners with $\mathbf{2 a}$ and $\mathbf{2 b}$. To avoid unwanted multiple insertion reactions, $2 a$ was placed in the servo-controlled syringe and ${ }^{[1] \mathrm{PF}_{6}}$ in the cell. Alkyne $\mathbf{2 b}$ presenting no troublesome reactivity would be placed in the cell and titrated by injections of $[1] \mathrm{PF}_{6}$.

ITC determination of reaction enthalpies. Due to the required long acquisition times, ITC experiment were carried out in an argon-filled glovebox with dry distilled $\mathrm{PhCl}$ as solvent, which was chosen for its low volatility and moderate polarity $(\varepsilon=5.62)$ allowing to reach sufficiently high concentrations in compound [1]PF 6 . The acquired ITC thermograms gave access to values of reaction enthalpy $\Delta H_{r}$ values. The latter were inferred from the sum of heat flow relative to the molar amount of reagent required to reach athermicity, since the studied reaction are reputedly irreversible. Of course the ITC heat flow data were corrected for the residual dilution occurring passed athermicity and, if relevant, for dilution heats probed in blank experiments. ${ }^{[26]}$ Complementary thermodynamic data can be deduced in principle by line fitting a thermochemical model to the plot of heat area vs mole ratio. The ITC thermochemical parameters are listed in Table 1. Examples of the corresponding ITC thermograms are shown in Figures 4-5 (cf. SI for additional ones). The raw $\Delta_{\mathrm{r}} H$ value of the systems [1]PF 6 /2a (ca. -28 $\mathrm{kcal} / \mathrm{mol}$ ) denotes a rather strongly exothermic chemical reaction. Applying the so-called "independent site" numerical line fitting mode ${ }^{[27]}$ did not provide an accurate value of the reaction $\Delta_{\mathrm{r}} G$ for the reaction of [1] $\mathrm{PF}_{6}$ with $\mathbf{2 a}$ due to a large error on the reaction entropy $\Delta_{r} S$. However, the fit value of the enthalpy, i.e $\Delta_{\mathrm{r}} H$ for the reaction of [1]PF 6 with $2 \mathrm{a}\left(\Delta_{\mathrm{r}} H \sim-31 \mathrm{kcal} / \mathrm{mol}\right)$ shows a good agreement with the raw $\Delta_{\mathrm{r}} H$ value. Considering the reaction of $[1] \mathrm{PF}_{6}$ with $\mathbf{2 b}$, the raw $\Delta_{\mathrm{r}} H$ value of $\sim-38 \mathrm{kcal} / \mathrm{mol}$ corresponds to the sum of all the processes occurring in solutio, that are the two successive alkyne insertion reactions and the successive acetonitrile decoordination-recoordination processes. Quite interestingly, the reaction of [1]PF 6 with $\mathbf{2 b}$ is only 10 $\mathrm{kcal} / \mathrm{mol}$ more exothermic than the reaction of [1]PF 6 with $2 \mathrm{a}$.

Table 1. Thermodynamic parameters obtained by ITC experiments for the reactions of [1] $\mathrm{PF}_{6}$ with $\mathbf{2} \mathbf{a}$ and $\mathbf{2} \mathbf{b}$. The fit values were obtained by applying the "independent site" model on integrated heat peaks.

\begin{tabular}{lcccc}
\hline System & $\begin{array}{r}\text { raw } \Delta_{\mathrm{r}} H \\
(\mathrm{kcal} / \mathrm{mol})\end{array}$ & $\begin{array}{c}\text { fit } \Delta_{\mathrm{r}} H \\
(\mathrm{kcal} / \mathrm{mol})\end{array}$ & $\begin{array}{c}\text { fit } \Delta_{\mathrm{r}} \mathrm{G} \\
(\mathrm{kcal} / \mathrm{mol})\end{array}$ & $\begin{array}{c}\text { fit } \Delta_{\mathrm{r}} S \\
(\mathrm{cal} / \mathrm{mol} . \mathrm{K})\end{array}$ \\
\hline$[1] \mathrm{PF}_{6} / \mathbf{2 a}$ & $-28 \pm 3$ & $-31 \pm 1$ & $-7 \pm 3$ & $-81 \pm 41$ \\
{$[1] \mathrm{PF}_{6} / \mathbf{2 b}$} & $-38 \pm 1$ & & & \\
\hline
\end{tabular}

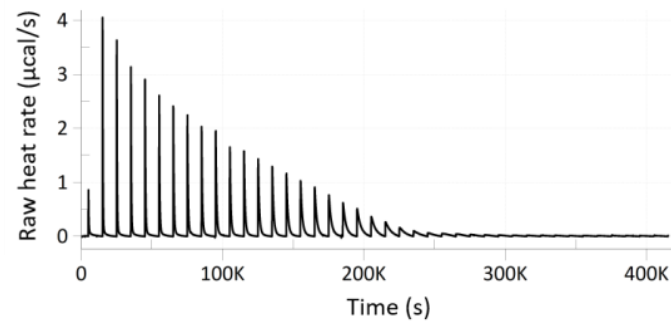

Figure 4. ITC thermogram of the reaction between [1]PF 6 (sample cell, $c=1.09 \mathrm{mM}$ ) and 2a (syringe, $c=25.4 \mathrm{mM}$ ) in chlorobenzene; the titration was performed at $25^{\circ} \mathrm{C}$ through 45 sequential additions (of $2.06 \mu \mathrm{L}$ each), the time delay between two consecutive injections was $10000 \mathrm{~s}$. The released heat is expressed in $\mu \mathrm{cal} / \mathrm{s}$ versus time in $\mathrm{s}$ 


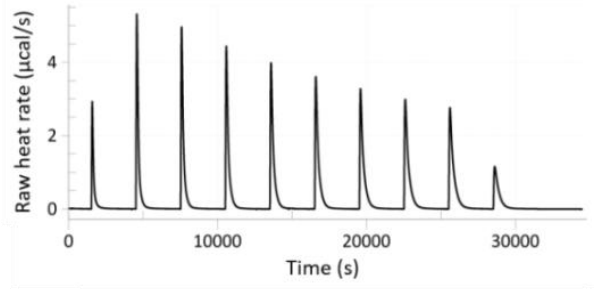

Figure 5. ITC thermogram of the reaction between $\mathbf{2 b}$ (sample cell, $\mathrm{C}=16.9$ $\mathrm{mM}$ ) and [1]PF $\mathrm{F}_{6}$ (syringe, $\mathrm{C}=2.3 \mathrm{mM}$ ) in chlorobenzene. The titration was performed at $25^{\circ} \mathrm{C}$ through 10 sequential additions (of $10.0 \mu \mathrm{L}$ first nine titrations and of $5.0 \mu \mathrm{L}$ the last one). Time between two consecutive injections was $3000 \mathrm{~s}$. Heat released is expressed in $\mu \mathrm{cal} / \mathrm{s}$ versus time in s.
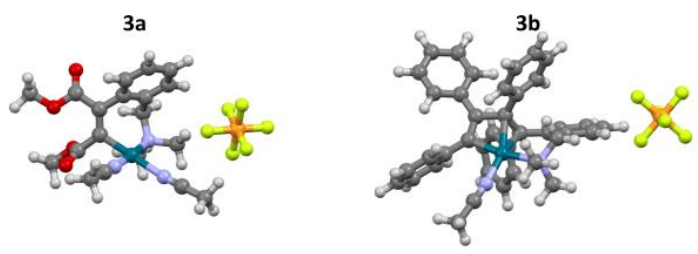

Figure 6. Singlet ground state optimized geometries of [3a]PF $F_{6}$ and $[3 \mathbf{b}] \mathrm{PF} \mathrm{F}_{6}$ at PBE-D3(BJ)/Def2-TZVP level of theory in chlorobenzene solution (PCM). Corresponding thermodynamic parameters are shown in Table 3. $\mathrm{P}$ : orange; $\mathrm{O}$ : red; F: yellow; N: violet; Pd: emerald green, C: grey; $\mathrm{H}$ : white; N: blue.

Table 2. DFT-D-computed thermochemical parameters (in $\mathrm{kcal} / \mathrm{mol}$ ) for the reactions of [1] $\mathrm{PF}_{6}$ with $\mathbf{2 a , b}$ supplemented with the association enthalpies for the explicit solvation of alkynes $\mathbf{2 a , b}$ by chlorobenzene (5) and the corrected thermodynamic parameters of the considered reactions (Scheme 1).

\begin{tabular}{lllllll} 
alkyne & $\Delta_{\mathrm{r}} H$ & $\Delta_{\mathrm{r}} G$ & $\Delta H_{\mathrm{es}}{ }^{\mathrm{a}}$ & $\Delta G_{\mathrm{es}}{ }^{\mathrm{a}}$ & $\Delta \Delta_{\mathrm{r}} H$ & $\Delta \Delta_{\mathrm{r}} G$ \\
\hline 2a & -43 & -28 & -4 & 5 & -33 & -35 \\
2b & -51 & -32 & -4 & 4 & -40 & -38 \\
\hline
\end{tabular}

$\Delta_{\mathrm{r}} H$ and $\Delta_{\mathrm{r}} G$ values correspond to the thermodynamic parameters of the reaction of palladacycle [1]PF 6 and alkynes 2a,b. $\Delta H_{\mathrm{es}}{ }^{\mathrm{a}}$ and $\Delta G_{\mathrm{es}}{ }^{\mathrm{a}}$ values correspond to the thermodynamic parameters for the explicit solvation of alkynes 2 a,b by $\mathrm{PhCl}$ (5), while $\Delta \Delta_{\mathrm{r}} H$ and $\Delta \Delta_{\mathrm{r}} G$ values are corrected thermodynamic parameters of the reaction of $[\mathbf{1}] \mathrm{PF}_{6}$ and $\mathbf{2 a , b}$ assuming a displacement of the chlorobenzene's assemblies, namely [5/[1]PF 6 and [5/2a,b] (see Scheme 1). Corresponding $\Delta S$ and $\Delta E$ values and optimized geometries are given in Supplementary Information. $\Delta H$ and $\Delta G$ values are expressed in $\mathrm{kcal} \mathrm{mol}^{-1}$. The calculations were performed at PBE-D3(BJ)/Def2TZVP level of theory in chlorobenzene (PCM) phase.

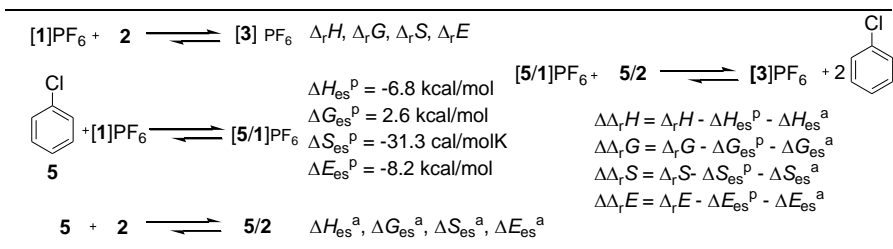

Scheme 1. Static DFT calculations performed at PBE-D3(BJ)/def2-TZVP level of theory with implicit solvation (PCM) provided the corrective enthalpy terms for the explicit solvation (labelled with "es" in subscript) of both the reactants ${ }^{[1] \mathrm{PF}_{6}}$ (labelled with " $p$ " in superscript) and 2a-b (labelled with "a" in superscript) by $\mathrm{PhCl}(5)$, allowing a comparison of experimental data with computed values.
Static DFT-D calculations of thermochemistry. The calculations were done on the systems [1] $\mathrm{PF}_{6} / \mathbf{2 a}-\mathbf{b}$. The results, i.e. thermodynamic parameters of the studied single/double insertion reaction sequences $\left(\Delta_{\mathrm{r}} H, \Delta_{\mathrm{r}} G\right.$, $)$ obtained by the performed calculations, are shown in Table 2. The related optimized geometries are displayed in Figure 6 . The resulting values of the reaction enthalpies $\Delta_{\mathrm{r}} H$ of both systems [1] $]^{+} / \mathbf{2 a}$ and [1] $\mathrm{PF}_{6} / \mathbf{2 b} \quad(-43 \mathrm{kcal} / \mathrm{mol}$ and $-51 \mathrm{kcal} / \mathrm{mol}$, respectively) are consistent with an energetically favoured chemical transformation. The difference of ca. $8 \mathrm{kcal} / \mathrm{mol}$ between the two reaction enthalpies recalls the $10 \mathrm{kcal} / \mathrm{mol}$ difference determined experimentally for $\Delta_{\mathrm{r}} H$ (Table 1). Regarding the computed Gibbs $\Delta_{\mathrm{r}} G$ energies $(-28 \mathrm{kcal} / \mathrm{mol}$ and $-32 \mathrm{kcal} / \mathrm{mol})$, both confirming the spontaneous nature of the reaction, are seemingly overestimated. In comparison to the ITC raw $\Delta_{\mathrm{r}} H$ values (ca. $-28 \mathrm{kcal} / \mathrm{mol}$ and $-38 \mathrm{kcal} / \mathrm{mol}$, Table 1) the computed $\Delta_{\mathrm{r}} H$ values seem to be overestimated as well. The reason for this discrepancy might lay in the insufficient correction for solvation operated by continuum screening models such as $\mathrm{PCM}$ or COSMO. Due to its polarizability the interaction of chlorobenzene with the substrate ${ }^{[8 a, 28]}$ may occur by $\pi$-stacking with the metallacycle. ${ }^{[29]}$ Chlorobenzene is indeed known to establish a range of noncovalent interactions with itself ${ }^{[30]}$ and other molecular or atomic partners ${ }^{[31]}$ in the gas or liquid phase. ${ }^{[32]}$ However, the relevance of such explicit interactions is hardly either predictable or detectable from NMR data or ITC outputs. In a number of previous reports of our's such an explicit interference of $\mathrm{PhCl}$ was a priori not considered as no significant discrepancy between ITC-determined and static COSMO/PCMDFT computed reaction enthalpies were noted. ${ }^{[1 a, 4 a, 5]}$

Therefore, an additional set of calculations accounting for explicit solvation by $\mathrm{PhCl}$ was performed, where the latter is engaged in $\pi$-stacks with both [1]PF 6 and the alkynes. Schematic representations of the performed calculations are given in Scheme 1, while the results of the additional calculations are reported in Table 2. These data are purely informative of the effect of explicit solvation on the thermochemistry of the Pd-C alkyne insertion reaction treated here and do not represent in our view an ultimate representation of the reality. When explicit solvation of both reactants ([1]PF 6 and $\mathbf{2 a - b}$ ) by chlorobenzene is accounted for, that is by assuming the $\pi$-stacking interaction of one $\mathrm{PhCl}$ with each reactant to give [3a-b]PF 6 the computed thermodynamic values (Table 2) tend to converge with the experimental ones rather clearly (Table 1 ). The corrected thermodynamic parameters of the insertions of alkynes $2 \mathbf{2}-\mathbf{b}$ into palladacycle [1]PF 6 that account for energies of association between chlorobenzene and the reactants $\left([\mathbf{1}] \mathrm{PF}_{6}\right.$ and $\left.\mathbf{2} \mathbf{a}-\mathbf{b}\right)$ in the way shown in Scheme 1, are $-33 \mathrm{kcal} / \mathrm{mol}$ and $-40 \mathrm{kcal} / \mathrm{mol}$, respectively.

\section{Conclusion}

The single and double insertions of alkynes 2a-b (Eqn 1-2) into palladacycle [1] $\mathrm{PF}_{6}$ were investigated by experimental Titration Calorimetry dubbed with theoretical investigations based on static Density Functional Theory (DFT) using Grimme's dispersion corrections - i.e D3(BJ) and D4(EEQ). ${ }^{1} \mathrm{H}$ NMR monitoring experiments showed that the single insertion of the alkyne $2 \mathrm{a}$ into the palladacycle [1] $\mathrm{PF}_{6}$ depends on a strict control of the concentration of alkyne. With a nearly stoichiometric ratio 
of reactants a second insertion may occur. On the other hand, the double insertion of $\mathbf{2 b}$ into [1]PF 6 depends on the concentration of the alkyne, giving only the doubly inserted product owing to a favoured second insertion step, like suggested by PBE-D4(EEQ) modelling of the reaction energy profile. The latter confirms earlier conclusions made on a slightly different system of chloridopalladium metallacycles that was stating that the first insertion is rate limiting. ${ }^{[20]}$ DFT reaction energy profiles suggest that the observation and persistence of the product of single insertion seems to depend on the thermodynamic stability of the product obtained upon the recoordination of an acetonitrile molecule after the first alkyne insertion: a more favourable coordination of an alkyne like shown with $\mathbf{2 b}$ to the product of single insertion would readily lead to a second alkyne insertion in a reactive C-Pd bond.

The ITC-determined enthalpies $\Delta_{\mathrm{r}} H$ of both studied reactions of single (raw $\Delta_{\mathrm{r}} H$ value of the system [1] $\mathrm{PF}_{6} / 2 \mathrm{a}$ is ca. $-28 \mathrm{kcal} / \mathrm{mol}$ ) and double (raw $\Delta H_{\mathrm{r}}$ value of the system [1] $\mathrm{PF}_{6} / \mathbf{2 b}$ is ca. -38 $\mathrm{kcal} / \mathrm{mol}$ ) insertion of alkynes into the palladacycles are however much lower than the one computed by DFT-D using the relatively reliable $\mathrm{PBE}$ functional and widely used conventional continuum screening solvation models, i.e COSMO and PCM. It is now obvious in the case of the synthesis of $[\mathbf{3 b}] \mathrm{PF}_{6}$ that two factors are particularly influential in the values of the computed reaction enthalpies. First, omission of the $\mathrm{PF}_{6}^{-}$counter-anion causes a drastic overestimation of the $\Delta_{\mathrm{r}} H$ with respect to the experimental value. Second, not accounting for explicit solvation causes a ca. $60 \%$ overestimation of $\Delta_{r} H$ when the counter-anion is included in the computed thermochemistry. The use of continuum solvation is often recommended to draw reaction energy profiles as it is generally admitted that medium's polarity may potentially influence activation energy barriers and reaction enthalpies. However, if accuracy of a reaction energy profile of a reaction mechanism is a goal, the results disclosed herein suggest that the pertinence of any DFT modelling of implicit and explicit solvation should be probed against reaction enthalpies experimentally determined by ITC whenever practically amenable. Indeed, comparing ITC data to continuum solvation-DFT-D data might reveal the unexpected explicit solvation of analytes, which might be an important information in mechanistic investigations.

\section{Experimental Section}

Experimental Details. General. All 1D NMR measurements ( ${ }^{1} \mathrm{H}(300,400$ 500 , and $600 \mathrm{MHz}$ ) and ${ }^{13} \mathrm{C}(75$ and $126 \mathrm{MHz})$ were performed on Bruker DPX 300 and 400, Avance I 500, or Avance III 600 spectrometers using chloroform- $d_{1}$. NMR spectra were recorded at $25^{\circ} \mathrm{C}$ and referenced to the residual proton and carbon signals of the deuterated solvent. All used compounds were stored and used into a dry and argon filled glove box or under argon. Chlorobenzene was purchased from Sigma Aldrich and distilled over calcium hydride and degassed prior to use. Alkynes $(\mathbf{2} \mathbf{a}, \mathbf{b})$ were purchased from Sigma Aldrich and used as received after checking their purity by NMR. If needed a purification of the alkynes was done by filtration through silica with pentane as eluent. The palladacycle $\left([1] \mathrm{PF}_{6}\right)$ was prepared by a modified literature procedure. ${ }^{[22]}$ Palladium chloride, lithium chloride, $N, N$-dimethyl-1-phenylmethanamine, triethylamine were purchased from Sigma Aldrich and used as received. All used solvents in the synthesis and reaction tests $\left(\mathrm{CH}_{2} \mathrm{Cl}_{2}, \mathrm{MeOH}\right.$, $\mathrm{MeCN}$, pentane, $n$-hexane) were purchased from Sigma Aldrich and distilled over an appropriate drying agent prior to use. Deuterated chloroform was purchased from Sigma Aldrich and dried through neutral alumina prior to use.

X-Ray diffraction analysis details. Structural X-Ray diffraction analysis was performed on the Bruker APEX II DUO Kappa-CCD diffractometer equipped with an Oxford Cryosystem liquid N2 device, using Mo Ka radiation $(\lambda=0.71073 \AA)$. The crystal-detector distance was $38 \mathrm{~mm}$. The cell parameters were determined (APEX2 software) from reflections taken from 3 sets of 12 frames, each at $10 \mathrm{~s}$ exposure. The structures were solved by direct methods using the program SHELXS-2013.2. The refinement and all further calculations were carried out using SHELXL2013. Recording and resolving of the crystal structures were done by the X-Ray structural diffraction analysis service of the University of Strasbourg. For more details on the resolution of crystal structures (Supplementary Information).

ITC experimental details. Experiments were carried out on a WatersSAS nano-ITC device ${ }^{[33]}$ (TA Instruments $\AA$ ) equipped with two stainless steel Hastelloy cells of $1 \mathrm{~mL}$ volume each). Auto equilibration of the ITC was performed before every experiment to reach an acceptable baseline. The solutions of the reactants $\left([\mathbf{1}] \mathrm{PF}_{6}\right.$ and $\left.\mathbf{2 a - b}\right)$ were prepared by dissolving a mass of substrate in pure, freshly distilled and degassed chlorobenzene. The ITC experiments were performed by sequential injection at $25^{\circ} \mathrm{C}$ with a moderate stirring rate $(150-200 \mathrm{rpm})$. Due to the nature of the investigated reactions, two distinct ITC experiments were performed. For the first one that considered the reaction of the palladacycle $\left([1] \mathrm{PF}_{6}\right)$ with the alkyne $\mathbf{2 a}$, the solution of the complex was loaded in the ITC sample cell while the servo-controlled ITC syringe (100 $\mu \mathrm{L})$ contained the solution of the alkyne $2 \mathbf{a}$. The reference cell $(1.0 \mathrm{~mL})$ was entirely filled with pure $\mathrm{PhCl}$. The concentration of $[1] \mathrm{PF}_{6}$ in pure $\mathrm{PhCl}$ was $1.1 \mathrm{mmol} / \mathrm{L}$, while the concentration of $2 \mathrm{a}$ solution was 25.3 $\mathrm{mmol} / \mathrm{L}$. The content of the syringe was injected into the sample cell in 45 injections $(2.06 \mu \mathrm{L}$ per injection) with a time delay between two consecutive injections of either 3.000 s or 10.000 s. For the second ITC experiment considered the reaction of palladacycle [1] $\mathrm{PF}_{6}$ with alkyne $\mathbf{2 b}$, the solution of [1] $\mathrm{PF}_{6}$ in pure $\mathrm{PhCl}$ being placed in the servo-controlled ITC syringe $(100 \mu \mathrm{L})$ while the ITC sample cell was loaded with the solution of the alkyne $\mathbf{2 b}$. The reference cell $(1.0 \mathrm{~mL})$ was entirely filled with pure $\mathrm{PhCl}$. As the experiments used a large excess of the alkyne $\mathbf{2 b}$, the concentration of the alkyne solution in pure $\mathrm{PhCl}$ span from 3.3 $\mathrm{mmol} / \mathrm{L}$ to $16.9 \mathrm{mmol} / \mathrm{L}$, while the concentration of the solution of [1]PF 6 were $2.3 \mathrm{mmol} / \mathrm{L}$. The content of the syringe was injected into the sample cell in 10 injections (first nine of $10.06 \mu \mathrm{L}$ per injection while tenth of $5.03 \mu \mathrm{L}$ ) with a time delay between two consecutive injections of 3000 $\mathrm{s}$. For each studied system at least three experiments under the same conditions were done. The heat of dilution of $2 \mathrm{a}$ and $[1] \mathrm{PF}_{6}$ in neat $\mathrm{PhCl}$ was also estimated in blank experiments (e.g. the titration of 2a and [1] $\mathrm{PF}_{6}$ in pure $\mathrm{PhCl}$, respectively) performed under conditions identical to that of the main experiment. The obtained heat of dilutions of $\mathbf{2 a}$ and $[1] \mathrm{PF}_{6}$, respectively, were systematically subtracted from all the corresponding titration curves carried out in presence of the palladacycle $\left([\mathbf{1}] \mathrm{PF}_{6}\right)$ and alkyne $(\mathbf{2 b})$, respectively. The enthalpy of reaction $\left(\Delta H_{r}\right)$ of the system $[1] \mathrm{PF}_{6} / \mathbf{2 a}$ was inferred by summing up the heat released till the stoichiometry point against the introduced molar content of $2 \mathbf{a}$, while $\Delta H_{r}$ of the system [1] $\mathrm{PF}_{6} / \mathbf{2 b}$ was obtained by summing up the heat released upon the first three injections against the molar content of [1] $\mathrm{PF}_{6}$ introduced during these three injections. Although the use of the fitting models on an irreversible reaction is not fully reliable, the ITC data of the [1] $\mathrm{PF}_{6} / \mathbf{2 a}$ experiments were fitted using the independent site $a d-$ hoc algorithm (implemented within NanolTC software), that provided an estimate of the thermodynamic parameters.

Static DFT-D thermochemistry calculations details. All computations were performed by the methods of the density functional theory (DFT) using the Gaussian 09 program package ${ }^{[34]}$. All geometry optimizations and interaction energies were obtained using Perdew-Burke-Ernzerhof $(\mathrm{PBE})^{[35]}$ functional augmented with Grimme's $\mathrm{D}^{\left[{ }^{[36]}\right.}$ inclusion of mid-tolong range dispersion force with a Becke-Johnson (BJ). ${ }^{[21]}$ All 
computations were carried out with Karlsruhe's valence polarized triple- $\zeta$ (def2-TZVP) basis set. ${ }^{[37]}$ Implicit solvation by chlorobenzene was accounted for by employing the standard Polarizable Continuum Model $(\mathrm{PCM})^{[38]}$ with default solvent parameters. All geometry optimizations by energy gradient minimization were carried out with ultra-fine integration grid accuracy, an energy gradient convergence criterion of $1 \mathrm{e}^{-3}$ au and tight SCF convergence criterion $\left(1 \mathrm{e}^{-7} \mathrm{au}\right)$. All the geometry optimizations were confirmed as true energy minima by calculating vibrational modes. Calculations of vibrational modes (analytical second derivative of vibrational frequencies) ${ }^{[39]}$ were performed at $298.15 \mathrm{~K}$ at the same level of theory as the geometry optimizations calculations (PBE-D3(BJ)/def2TZVP level). The vibrational modes were also computed to produce for thermodynamic parameters of the systems, namely internal energy and entropy, by statistical thermal analysis. Enthalpies and Gibbs free energies of the systems were deduced from the internal energies and entropies. Reaction enthalpies $\left(\Delta_{\mathrm{r}} H\right)$, Gibbs free energies $\left(\Delta_{\mathrm{r}} G\right)$ and entropies $\left(\Delta_{r} S\right)$ of the pair formation are estimated as a difference between corresponding values of the pair and free reactants. Interaction energies $\left(\Delta_{r} E\right)$ were obtained in the same manner. Starting geometries of the reactants $\left([\mathbf{1}] \mathrm{PF}_{6}\right.$ and $\left.\mathbf{2} \mathbf{a}-\mathbf{b}\right)$ and of the reaction products ([3a]PF and $[3 \mathbf{b}] P F_{6}$ ) were taken from the Cambridge Structural Database (CSD) or constructed from similar structures and optimized as singlet ground states in a chlorobenzene solution (PCM conductor like screening model of solvation). Starting geometries of explicitly solvated reactants ([1] $\mathrm{PF}_{6} / \mathrm{PhCl},[1] \mathrm{PF}_{6} / 2 \mathrm{PhCl}, 2 \mathrm{a} / \mathrm{PhCl}, \mathbf{2 b} / \mathrm{PhCl}$ and $2 \mathrm{~b} / 2 \mathrm{PhCl}$ ) were constructed from previously optimized reactants ([1]PF 6 and $\mathbf{2 a - b})$ and chlorobenzene and optimized as singlet ground states in the chlorobenzene solution (PCM) phase. Graphical representations of molecular structures were drawn using Mercury v3.9. $1^{[40]}$

Static DFT-D energy profile for the formation of $3 b$ and $3 a$. All geometry optimizations of the reactants, intermediates, transition states and products were carried out for the investigation of the reaction mechanism of formation of $[\mathbf{3 b} / \mathbf{3} \mathbf{a}]^{+}$by insertion of $\mathbf{2 b} / \mathbf{2 a}$ in $[\mathbf{1}]^{+}$were performed using the SCM-ADF2019.01 package ${ }^{[41]}$, at the DFT level. The PBE functional augmented with Grimme's dispersion correction with the electronegativity equilibrium model (DFT-D4(EEQ) $)^{[42]}$ was used in all computations. All geometry optimizations were carried out in the singlet spin-state using scalar relativistic effects (Zeroth Order relativistic Approximation $^{[25]}$ ) with ad hoc all-electron single polarization function triple- $\zeta$ Staler-type basis set $(\mathrm{TZP})^{[25,43]}$. Solvation was accounted for using the Conductor-like Screening Model $(\mathrm{COSMO})^{[13]}$ procedure assuming the user-defined chlorobenzene $(\varepsilon=5.62, r=3.48 \AA$ ) as a solvent. Geometry optimizations by energy gradient minimization were carried out in all cases with integration accuracy "Normal". All transition states were found using the Nudged Elastic Band (NEB) ${ }^{[44]}$ procedure. Vibrational modes were analytically computed to verify that the optimized geometries were related to energy minima or to transition states.

Synthesis of [1]PF 6 . The compound was synthetized by the following a procedure inspired from literature. ${ }^{[22]}$ Into the solution containing the the chloropalladacycle of $\mathrm{N}, \mathrm{N}$-dimethylbenzylamine $(0.5 \mathrm{mmol})$ and $2 \mathrm{~mL}$ of MeCN in $20 \mathrm{~mL}$ of $\mathrm{CH}_{2} \mathrm{Cl}_{2}$, the solution that contained $\mathrm{AgPF}_{6}(1.0 \mathrm{mmol})$ and $1 \mathrm{~mL}$ of $\mathrm{MeCN}$ in $5 \mathrm{~mL}$ of $\mathrm{CH}_{2} \mathrm{Cl}_{2}$ was added. These solutions were prepared in separate Schlenk tubes. The resulting mixture was allowed to stir for few minutes, i.e. until the formation of a precipitate $(\mathrm{AgCl})$ was observed. The mixture was filtrated through Celite. The solvents of the resulting solution were evaporated under reduced pressure. The crude product was then dissolved in minimal amount of $\mathrm{CH}_{2} \mathrm{Cl}_{2}$ and around 2 $\mathrm{mL}$ of pentane was added in order to induce precipitation of the product. After adding the additional $5 \mathrm{~mL}$ of pentane the solvent was decanted and the product was dried under reduced pressure for two hours. The product was obtained as a pale-brown powder (yield: $91 \%$ ). Elem. anal. calcd for $\mathrm{C}_{13} \mathrm{H}_{18} \mathrm{~N}_{3} \mathrm{PdF}_{6} \mathrm{P}(\%)$ : C 33.39, $\mathrm{H}$ 3.88, N 8.98. Found: $\mathrm{C} 33.50$, $\mathrm{H}$ 4.02, N 8.56. ${ }^{1} \mathrm{H}$ NMR (300 MHz, $\left.\mathrm{CDCl}_{3}, \delta, \mathrm{ppm}\right) 7.09-6.84(\mathrm{~m}, 4 \mathrm{H})$, $3.91(\mathrm{~s}, 2 \mathrm{H}), 2.80(\mathrm{~s}, 6 \mathrm{H}), 2.44(\mathrm{~s}, 3 \mathrm{H}), 2.34(\mathrm{~s}, 3 \mathrm{H}) .{ }^{11 \mathrm{~b}}{ }^{13} \mathrm{C}$ NMR $(126$ $\left.\mathrm{MHz}, \mathrm{CDCl}_{3}\right) \delta 147.15,133.43,126.00,125.92,122.43,120.53,73.21$, 52.56, 3.34, 2.43. HR MS (ESI+) calcd for $\left[\mathrm{C}_{13} \mathrm{H}_{18} \mathrm{~N}_{3} \mathrm{Pd}\right]^{+}: \mathrm{m} / z 322.0530$. Found : 322.0532
Synthesis of [3a]PF $F_{6}$. Compound [1]PF 6 was synthesized according to a published procedure ${ }^{[18 c]}$ while $\mathrm{AgPF}_{6}$ was used instead of $\mathrm{AgBF}_{4}$. The palladacycle $\left([1] \mathrm{PF}_{6}\right)(0.1 \mathrm{mmol})$ was dissolved in $10 \mathrm{~mL}$ of $\mathrm{CH}_{2} \mathrm{Cl}_{2}$ and subsequently a $\mathrm{CH}_{2} \mathrm{Cl}_{2}$ solution containing the alkyne 2a (14.2 mg, 0.1 $\mathrm{mmol}$ in $1 \mathrm{~mL}$ ) was added. After stirring the reaction mixtures for 90 minutes, the solvent was evaporated under reduced pressure. The resulting yellow residue, relatively reactive and unstable in solution, was triturated and washed thrice with $5 \mathrm{~mL}$ of cold $n$-hexane affording a yellow-orange product that was consecutively dried under reduced pressure for several hours (yield: 64\%). Elem. anal. calcd for $\mathrm{C}_{19} \mathrm{H}_{24} \mathrm{~N}_{3} \mathrm{O}_{4} \mathrm{PdPF}_{6} \bullet 5 / 2 \mathrm{CH}_{2} \mathrm{Cl}_{2} \bullet 7 / 2 \mathrm{CH}_{3} \mathrm{CN}(\%)$ : C 32.54, H 3.55, N 8.66. Found: C 32.43, H 3.78, N 8.79. ${ }^{1} \mathrm{H}$ NMR (400 MHz, CDCl3): $\delta 7.68$ (d, J $=8 \mathrm{~Hz}, 1 \mathrm{H}), 7.55(\mathrm{t}, J=7 \mathrm{~Hz}, 1 \mathrm{H}), 7.48-7.36(\mathrm{~m}, 1 \mathrm{H}), 7.32(\mathrm{~d}, J=7 \mathrm{~Hz}$, $1 \mathrm{H}), 3.83(\mathrm{~d}, J=12 \mathrm{~Hz}, 1 \mathrm{H}), 3.83(\mathrm{~d}, 6 \mathrm{H}), 2.99(\mathrm{~d}, J=12 \mathrm{~Hz}, 1 \mathrm{H}), 2.96(\mathrm{~s}$ $3 \mathrm{H}), 2.90(\mathrm{~d}, J=5 \mathrm{~Hz}, 1 \mathrm{H}), 2.56(\mathrm{~s}, 3 \mathrm{H}), 2.26(\mathrm{~d}, J=15 \mathrm{~Hz}, 6 \mathrm{H}) .{ }^{13} \mathrm{C}$ NMR $\left(126 \mathrm{MHz}, \mathrm{CDCl}_{3}\right): \delta 169.76,161.78,153.61,137.90,132.39$, $131.60,131.53,130.71,129.51,128.13,121.42,67.62,57.62,52.58$, $52.51,3.18,2.18$

Synthesis of [3b]PF 6 . Palladacycle [1] $\mathrm{PF}_{6}(0.100 \mathrm{~g}, 0.2 \mathrm{mmol})$ was dissolved in $10 \mathrm{~mL}$ of $\mathrm{CH}_{2} \mathrm{Cl}_{2}$ and subsequently the solution that contained $(0.0930 \mathrm{~g}, 0.4 \mathrm{mmol})$ of the alkyne $\mathbf{2 b}$ in $1 \mathrm{~mL}$ of $\mathrm{CH}_{2} \mathrm{Cl}_{2}$ was added. After stirring the reaction mixture for 60 minutes, the solvent was evaporated under reduced pressure. The resulting yellow residue was triturated and washed thrice with cold $5 \mathrm{~mL}$ of $n$-hexane. After evaporation of $n$-hexane under reduced pressure, a yellow-orange product appeared. Consecutively, the product was dried under reduced pressure for several hours (yield: $80 \%$ ). Elem. anal. calcd for $\mathrm{C}_{39} \mathrm{H}_{35} \mathrm{~N}_{2} \mathrm{PdF}_{6} \mathrm{P} \cdot 1 / 3 \mathrm{CH}_{2} \mathrm{Cl}_{2} \cdot \mathrm{CH}_{3} \mathrm{CN}(\%): \mathrm{C} 57.45, \mathrm{H}$ 4.37, N 3.78. Found: C 57.06, H 4.41, N 3.86. ${ }^{1} \mathrm{H}$ NMR $\left(500 \mathrm{MHz}, \mathrm{CDCl}_{3}\right)$ : $\delta 7.45-7.13(\mathrm{~m}$, 24H), $7.07-6.89(\mathrm{~m}, 3 \mathrm{H}), 6.62(\mathrm{~d}, J=9 \mathrm{~Hz}, 1 \mathrm{H}), 2.78(\mathrm{~s}, 2 \mathrm{H}), 2.53(\mathrm{~d}, J$ $=139 \mathrm{~Hz}, 6 \mathrm{H}), 1.96(\mathrm{~s}, 6 \mathrm{H}) \cdot{ }^{11 \mathrm{~b}}{ }^{13} \mathrm{C}$ NMR $\left(126 \mathrm{MHz}, \mathrm{CDCl}_{3}\right): \delta 148.04$, $146.48,139.26,137.37,137.16,137.09,134.92,134.26,133.35,131.88$, $129.79,129.57,129.49,129.11,128.42,127.83,127.56,127.35,126.76$, 126.18, 77.41, 77.16, 76.91, 67.14, 52.18, 46.52, 2.54. HR MS (ESI+): $637.18\left(\left[\mathrm{C}_{39} \mathrm{H}_{35} \mathrm{~N}_{2} \mathrm{Pd}\right]^{+}\right), \mathrm{m} / z 595.15\left(\left[\mathrm{C}_{39} \mathrm{H}_{35} \mathrm{~N}_{2} \mathrm{Pd}\right]^{+}-\mathrm{MeCN}\right)$.

Monitored synthesis of [3a]PF . Palladacycle [1]PF $6(0.1 \mathrm{mmol})$ and alkyne 2a $(0.2 \mathrm{mmol})$ were separately dissolved into $2.5 \mathrm{~mL}$ and $1.0 \mathrm{~mL}$ of deuterated chloroform, respectively. The solution of the alkyne was sequentially injected into the stirred solution of palladacycle. ${ }^{1} \mathrm{H}$ NMR spectra was recorded immediately after injection of 1 eq of the alkyne as well as after 3.5 hours. Additionally, the reaction was monitored by ${ }^{1} \mathrm{H}$ NMR upon adding of 2 eqv of alkyne within $1 \mathrm{~h}$ and $15 \mathrm{~h}$ of the reaction time.

Monitored formation of [3b]PF 6 . Palladacycle [1]PF 6 (46.8 mg, 0.1 $\mathrm{mmol}$ ) and alkyne $\mathbf{2 b}(178.2 \mathrm{mg}, 1.0 \mathrm{mmol})$ were separately dissolved into $2.5 \mathrm{~mL}$ and $3.0 \mathrm{~mL}$ of deuterated chloroform, respectively. The solution of alkyne was sequentially injected into the stirred solution of the palladacycle. The reaction was monitored by ${ }^{1} \mathrm{H}$ NMR upon adding of 1 10 eq of alkyne within $0.7 \mathrm{~h}$ to $24 \mathrm{~h}$ of the reaction time.

Supporting Information. NMR Spectra, ITC thermograms and theoretical details. Deposition numbers for [1]PF 6 (CCDC 2040876) and [3b]PF 6 (CCDC 2040877) contain the supplementary crystallographic data for this paper. These data are provided free of charge by the joint Cambridge Crystallographic Data Centre and Fachinformationszentrum Karlsruhe Access Structures service www.ccdc.cam.ac.uk/structures.

Acknowledgements. The CNRS and the University of Strasbourg are thanked for their support. M.M. thanks Campus 
France and the Fund for young talents - Dositeja for financial support. Funding: This work was supported by the Agence Nationale de la Recherche through the ANR-DFG grant COCOORDCHEM and by the Serbian Ministry of Education, Science and Technological Development (Contract numbers: 451-03-9/2021-14/200168 and 451-03-9/2021-14/200288). HPC resources and services used in this work were provided by the IT Research Computing group in Texas A\&M University at Qatar and from GENCI-IDRIS-France (Grant 2020-A0080811408).

\section{Keywords: Calorimetry • Density functional calculations • Palladium • Metallacycles $\bullet$ Insertion}

[1] a) A. Hansen, C. Bannwarth, S. Grimme, P. Petrovic, C. Werle, J.-P Djukic, ChemistryOpen 2014, 3, 177-189; b) L. Kaufmann, E. V. Dzyuba, F. Malberg, N. L. Loew, M. Groschke, B. Brusilowskij, J. Huuskonen, K. Rissanen, B. Kirchner, C. A. Schalley, Org. Biomol Chem. 2012, 10, 5954-5964.

[2] a) S. Grimme, J. Comput. Chem. 2006, 27, 1787-1799; b) S. Grimme S. Ehrlich, L. Goerigk, J. Comp. Chem. 2011, 32, 1456-1465; c) E. Caldeweyher, J.-M. Mewes, S. Ehlert, S. Grimme, Phys. Chem. Chem Phys. 2020, 22, 8499-8512.

[3] a) E. Freire, O. L. Mayorga, M. Straume, Anal. Chem. 1990, 62, 950A959A; b) A Velázquez-Campoy, H. Ohtaka, A Nezami, S. Muzammil, E. Freire, Curr. Prot. Cell Biol. 2004, 23, 17.18.11-17.18.24

[4] a) M. Hamdaoui, M. Ney, V. Sarda, L. Karmazin, C. Bailly, N. Sieffert, S. Dohm, A. Hansen, S. Grimme, J.-P. Djukic, Organometallics 2016 35, 2207-2223; b) M. Diab, S. Floquet, M. Haouas, P. A. Abramov, X Lopez, D. Landy, A. Damond, C. Falaise, V. Guerineau, D. Touboul, D. Naoufal, E. Cadot, Eur. J. Inorg. Chem. 2019, 2019, 3373-3382; c) Q. $\mathrm{He}, \mathrm{M}$. Kelliher, S. Bahring, V. M. Lynch, J. L. Sessler, J. Am. Chem. Soc. 2017, 139, 7140-7143; d) A. Tesmar, I. Anusiewicz, L. Chmurzynski, Struct. Chem. 2017, 28, 1723-1730; e) L. Xu, A. Zhang Y. Lu, H. Yang, Z. Liu, RSC Adv. 2016, 6, 99859-99866.

[5] M. R. Milovanovic, S. D. Zaric, Y. Cornaton, J.-P. Djukic, J. Organomet Chem. 2020, 929, 121582

[6] M. Garcia-Ratés, F. Neese, J. Comput. Chem. 2020, 41, 922-939.

[7] a) J. Tomasi, B. Mennucci, R. Cammi, Chem. Rev. 2005, 105, 2999 3094; b) G. J. Tawa, R. L. Martin, L. R. Pratt, T. V. Russo, J. Phys Chem. 1996, 100, 1515-1523.

[8] a) M. R. Milovanovic, Q. Dherbassy, J. Wencel-Delord, F. Colobert, S. D. Zaric, J.P. Djukic, ChemPhysChem 2020, 21, 2136-2142; b) P. V. Petrovic, S. Grimme, S. D. Zaric, M. Pfeffer, J.-P. Djukic, Phys. Chem Chem. Phys. 2014, 16, 14688-14698; c) W. Iali, P. Petrovic, M. Pfeffer S. Grimme, J.-P. Djukic, Dalton Trans. 2012, 41, 12233-12243.

[9] C. P. Kelly, C. J. Cramer, D. G. Truhlar, J. Phys. Chem. A 2006, 110 2493-2499.

[10] M. Steiner, T. Holzknecht, M. Schauperl, M. Podewitz, Molecules 2021, 26, 1793.

[11] O. Hollóczki, A. Berkessel, J. Mars, M. Mezger, A. Wiebe, S. R. Waldvogel, B. Kirchner, ACS Catalysis 2017, 7, 1846-1852.

[12] M. Cossi, N. Rega, G. Scalmani, V. Barone, J. Comput. Chem. 2003, 24, 669-681.

[13] a) A. Klamt, G. Schüürmann, J. Chem. Soc., Perkin Trans. 2 1993, 799-805; b) A. Klamt, J. Phys. Chem. 1995, 99, 2224-2235; c) A Klamt, V. Jonas, J. Chem. Phys. 1996, 105, 9972-9981.

[14] A. Klamt, J. Phys. Chem. 1995, 99, 2224-2235.

[15] Palladacycles. Synthesis, Characterization and Applications, WileyVCH Verlag GmbH, Weinheim, 2008

[16] H. Takahashi, J. Tsuji, J. Organomet Chem. 1967, 10, 511-517.

[17] M. Pfeffer, Rec.Trav. Chim. Pays-Bas 1990, 109, 567-576.

[18] a) A. Bahsoun, J. Dehand, M. Pfeffer, M. Zinsius, S.-E. Bouaoud, G. Le Borgne, J. Chem. Soc., Dalton Trans. 1979, 547-556; b) C. Arlen, M. Pfeffer, O. Bars, G. Le Borgne, J. Chem. Soc., Dalton Trans. 1986 359-363; c) F. Maassarani, M. Pfeffer, G. Le Borgne, Organometallics 1987, 6, 2029-2043.

[19] a) J. M. Vila, M. T. Pereira, in Palladacycles: Synthesis, Characterization and Applications (Eds.: J. Dupont, M. Pfeffer), WileyVCH, Weinheim, 2008, p. 87; b) J. Dupont, C. S. Consorti, J. Spencer, Chem. Rev. 2005, 105, 2527-2572; c) F. Xu, Y.-Y. Song, H.-M. Zhou, C.-S. Liu, Y.-Z. Lu, J.-P. Du, J. Organomet. Chem. 2020, 924, 121461 d) P. Saxena, N. Thirupathi, M. Nethaji, Organometallics 2014, 33 5554-5565; e) J. Vicente, I. Saura-Llamas, J. Turpín, D. Bautista, C. R. de Arellano, P. G. Jones, Organometallics 2009, 28, 4175-4195; f) J. Albert, L. D'Andrea, J. Granell, J. Zafrilla, M. Font-Bardia, X. Solans, J. Organomet. Chem. 2007, 692, 4895-4902; g) L. Li, Y. Jiao, W. W Brennessel, W. D. Jones, Organometallics 2010, 29, 4593-4605; h) Y Lin, L. Gong, H. Xu, X. He, T. B. Wen, H. Xia, Organometallics 2009 28, 1524-1533; i) W. Ferstl, I. K. Sakodinskaya, N. Beydoun-Sutter, G.
Le Borgne, M. Pfeffer, A. D. Ryabov, Organometallics 1997, 16, 411418; j) A. J. Edwards, S. A. Macgregor, A. D. Rae, E. Wenger, A. C. Willis, Organometallics 2001, 20, 2864-2877.

[20] A. D. Ryabov, R. Van Eldik, G. Le Borgne, M. Pfeffer, Organometallics 1993, 12, 1386-1393.

[21] S. Grimme, S. Ehrlich, L. Goerigk, J. Comput. Chem. 2011, 32, 14561465.

[22] M. Pfeffer, A. B. Goel, Cyclopalladated Compounds, Vol. 26, John Wiley \& Sons, Inc., New York, 1989.

[23] J. Spencer, M. Pfeffer, Tetrahedron: Asymmetry 1995, 6, 419-426.

[24] a) J. J. Guerard, J. S. Arey, J. Chem. Theor. Comput. 2013, 9, 5046 5058; b) C. J. Cramer, D. G. Truhlar, Acc. Chem. Res. 2008, 41, 760 768.

[25] E. v. Lenthe, A. Ehlers, E. J. Baerends, J. Chem. Phys. 1999, 110 8943-8953.

[26] Applications of Calorimetry in a Wide Context, Intechopen, 2013.

[27] N. E. Grossoehme, A. M. Spuches, D. E. Wilcox, J. Biol. Inorg. Chem. 2010, 15, 1183-1191.

[28] a) V. P. Korolev, N. L. Smirnova, D. V. Batov, Russ. J. Appl. Chem 2006, 79, 213-218; b) Z. Friedl, J. Biros, O. Exner, J. Chem. Soc. Perkin Trans. 2 1990, 459-464.

[29] a) D. N. Sredojević, D. B. Ninković, G. V. Janjić, J. Zhou, M. B. Hall, S D. Zarić, ChemPhysChem 2013, 14, 1797-1800; b) D. P. Malenov, G V. Janjić, V. B. Medaković, M. B. Hall, S. D. Zarić, Coord. Chem. Rev. 2017, 345, 318-341; c) D. P. Malenov, S. D. Zarić, Dalton Trans. 2019, $48,6328-6332$.

[30] L. Muzangwa, S. Nyambo, B. Uhler, S. A. Reid, J. Chem. Phys. 2012 137,184307

[31] a) S. Sharma, B. Ahmed, M. Upadhyaya, M. J. Bezbaruah, I. Ali, B. Bezbaruah, Asian J. Chem. 2021, 33, 338-344; b) S. A. Reid, S Nyambo, A. Kalume, B. Uhler, C. Karshenas, L. Muzangwa, J. Phys Chem. A 2013, 117, 12429-12437; c) J.-J. Oh, I. Park, S. A. Peebles R. L. Kuczkowski, J. Mol. Struct. 2001, 599, 15-22; d) L.-H. Zhao, R.Q. Png, J.-M. Zhuo, L.-Y. Wong, J.-C. Tang, Y.-S. Su, L.-L. Chua, Macromolecules 2011, 44, 9692-9702.

[32] T. V. Bogdan, E. S. Alekseev, J. Struct. Chem. 2012, 53, 93-99.

[33] www.tainstruments.com

[34] M. J. Frisch, G. W. Trucks, H. B. Schlegel, G. E. Scuseria, M. A. Robb, J. R. Cheeseman, G. Scalmani, V. Barone, B. Mennucci, G. A Petersson, H. Nakatsuji, M. Caricato, X. Li, H. P. Hratchian, A. F. Izmaylov, J. Bloino, G. Zheng, J. L. Sonnenberg, M. Hada, M. Ehara, K. Toyota, R. Fukuda, J. Hasegawa, M. Ishida, T. Nakajima, Y. Honda, O. Kitao, H. Nakai, T. Vreven, J. A. M. Jr., J. E. Peralta, F. Ogliaro, M. Bearpark, J. J. Heyd, E. Brothers, K. N. Kudin, V. N. Staroverov, R Kobayashi, J. Normand, K. Raghavachari, A. Rendell, J. C. Burant, S. S. lyengar, J. Tomasi, M. Cossi, N. Rega, J. M. Millam, M. Klene, J. E. Knox, J. B Cross, V. Bakken, C. Adamo, J Jaramillo, R Gomperts, R. E. Stratmann, O. Yazyev, A. J. Austin, R. Cammi, C. Pomelli, J. W Ochterski, R. L. Martin, K. Morokuma, V. G. Zakrzewski, G. A. Voth, P. Salvador, J. J. Dannenberg, S. Dapprich, A. D. Daniels, Ö. Farkas, J. B Foresman, J. V. Ortiz, J. Cioslowski, D. J. Fox, (Ed.: I. Gaussian), Wallingford CT, 2009.

[35] J. P. Perdew, K. Burke, M. Ernzerhof, Phys. Rev. Lett. 1996, 77, 3865 3868.

[36] S. Grimme, J. Antony, S. Ehrlich, H. Krieg, J. Chem. Phys. 2010, 132, 154104.

[37] a) F. Weigend, R. Ahlrichs, Phys. Chem. Chem. Phys. 2005, 7, 3297 3305; b) F. Weigend, Phys. Chem. Chem. Phys. 2006, 8, 1057-1065.

[38] S. Miertuš, E. Scrocco, J. Tomasi, Chem. Phys. 1981, 55, 117-129.

[39] a) A. Bérces, R. M. Dickson, L. Fan, H. Jacobsen, D. Swerhone, T. Ziegler, Comput. Phys. Commun. 1997, 100, 247-262; b) H. Jacobsen A. Bérces, D. P. Swerhone, T. Ziegler, Comput. Phys. Commun. 1997, 100, 263-276.

[40] C. F. Macrae, I. J. Bruno, J. A. Chisholm, P. R. Edgington, P. McCabe E. Pidcock, L. Rodriguez-Monge, R. Taylor, J. van de Streek, P. A Wood, J. Appl. Cryst. 2008, 41, 466-470.

[41] G. t. Velde, F. M. Bickelhaupt, E. J. Baerends, C. F. Guerra, S. J. A. v. Gisbergen, J. G. Snijders, T. Ziegler, J. Comput. Chem. 2001, 22, 931 967.

[42] E. Caldeweyher, S. Ehlert, A. Hansen, H. Neugebauer, S. Spicher, C. Bannwarth, S. Grimme, J. Chem. Phys. 2019, 150, 154122

[43] a) E. v. Lenthe, E. J. Baerends, J. G. Snijers, J. Chem. Phys. 1993, 99 4597-4610; b) E. v. Lenthe, E. J. Baerends, J. G. Snijders, J. Chem. Phys. 1994, 101, 9783-9792.

[44] G. Henkelmann, B. P. Uberuaga, H. Jonsson, J. Chem. Phys. 2000 113, 9901-9904. 


\section{Entry for the Table of Contents}

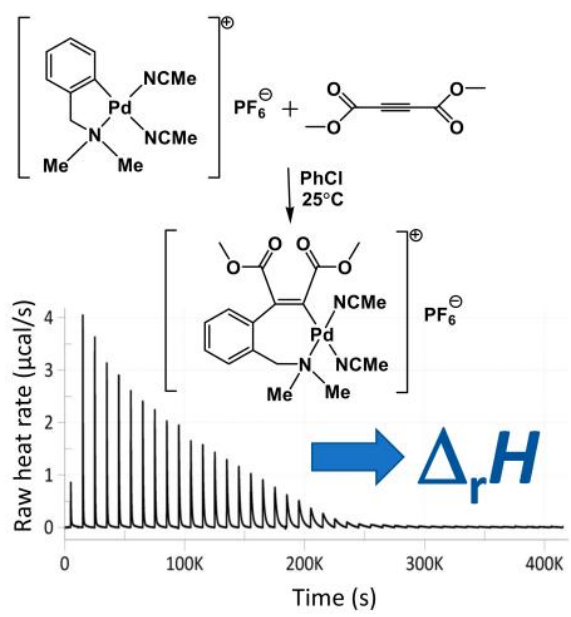

\section{TABLE OF CONTENT TEXT:}

Enthalpies of reactions of alkynes with a palladacycle determined by isotherm titration calorimetry in chlorobenzene reveal major solvation-related discrepancies with a standard continuum solvation-DFT approach. 